\title{
sciendo
}

\section{Suggestions for Judo Training with Pacing Strategy and Decision Making by Judo Championship Phases}

\author{
by \\ Bianca Miarka ${ }^{1,2}$, Ciro José Brito², John Amtmann ${ }^{3}$, Cláudio Córdova \\ Fabio dal Bello ${ }^{5}$, Suzi Camey ${ }^{6}$
}

\begin{abstract}
The present study aimed to compare pacing and decision making of athletes competing in judo, with particular attention paid to effort-pause ratios occurring in the championship phases of the Olympic Games and non-Olympic Games. The sample was composed of 53,403 sequential actions analyzed during 611 performances of the non-Olympic Games (eliminatory $n=330$, quarterfinals $n=60$, semi-final $n=88$, repechage $n=21$, third place playoff $n=26$, and final $n=79$ ) and 163 from the Olympic Games (eliminatory $n=71$, quarterfinals $n=13$, semi-final $n=26$, repechage $n$ $=20$, third place playoff $n=24$, and final $n=14$ ). The analysis of effort-pause ratios included separating bouts into states of approach, gripping, attack, groundwork and pause, according to frequency and time. A Markov multi-state model and analysis of variance were applied ( $p \leq 0.05)$. Approach time presented differences of the eliminatory Olympic Games (7.3 \pm 3.2 s) versus final non-Olympic Games (6.0 $\pm 2.2 s)$, and the third place playoff Olympic Games (8.1 \pm 2.3 s) versus semi-final (6.2 $\pm 2.4 \mathrm{~s})$ and third place playoff $(5.9 \pm 2.1 \mathrm{~s})$ of the non-Olympic Games, and the semi-final Olympic Games $(8.6 \pm 2.3 \mathrm{~s})$ versus eliminatory $(6.5 \pm 2.3 \mathrm{~s})$, quarter-finals $(6.5 \pm 1.7 \mathrm{~s})$, semi-final $(6.2 \pm 2.4 \mathrm{~s})$, repechage $(6.2 \pm 2.2 \mathrm{~s})$, third place playoff $(5.9 \pm 2.1 \mathrm{~s})$, and final $(6.0 \pm 2.0 \mathrm{~s})$ of the non-Olympic Games. Pause time presented differences of the semi-final Olympic Games $(6.8 \pm 2.1$ s) versus eliminatory (5.1 $\pm 3.1 \mathrm{~s})$. The present data suggest a focus on pacing strategy during championship phases, which mimic the requirements of judo combats.
\end{abstract}

Key words: pacing strategy, decision-making, task performance and analysis, sports psychology, martial arts.

\section{Introduction}

In quest of best performance and training, athletes, coaches and physical trainers have to decide about how and when the judo athlete has to invest their energy during the combat and competition (Baron et al., 2009; Smits et al., 2014). This concept is also known as pacing (Smits et al., 2014) and this phenomenon has not been investigated in judo championships. A full literature review did not produce any research addressing the ability to integrate decision making and pacing strategy based on self-paced actions during competitions. Due to difficulties in conducting physiological measurements during a match, studies interested in the physiological responses to judo have used time-motion analysis of the effort-pause (EP) ratio to determine the metabolic profile of judo matches (Miarka et al., 2016a; Slimani et al., 2016). However, to obtain information for conditioning and strength training, it is important to highlight that open task

\footnotetext{
1 - Physical Education School, Federal University of Pelotas, Brazil.

2 - Physical Education Department, Federal University of Juiz de For a, Brazil.

3 - Safety, Health and Industrial Hygiene Department, Montana Tech of the University of Montana, USA.

4 - Graduation Program in Physical Education, Catholic University of Brasília, Brazil.

5 - Head of Physical Activity and Sports Science Master Program, Universidad Santo Tomás, Santiago, Chile.

6 - Statistic Department, Mathematic Institute, Federal University of Rio Grande do Sul, Brazil.
} 
and intermittent sports involve complex sequential skills during moments of effort and pause (Calmet et al., 2010; Ostrowski et al., 2012; Courel et al., 2014; Escobar-Molina et al., 2014; Lech et al., 2015; Gołaś et al., 2016), with general values around 1530 s: 8-15 s per EP ratio (Franchini et al., 2013; Sterkowicz-Przybycien et al., 2017).

Contextual practices should consider that in the course of international competitions, judo medalists usually have between five and seven bouts lasting up to five minutes (Branco et al., 2013; Brito et al., 2017). In the event of a tie, it could be extended, with the win awarded to whoever scores the first point, and this is known as the golden score decision (Branco et al., 2013; Miarka et al., 2016b). Athletes begin the bout trying to gain an advantage through gripping (Calmet et al., 2010). Once a grip is secured, a throwing technique is applied (Courel et al., 2014; Kajmovic and Radjo, 2014), the bout could end with the maximum score of ippon (knockout/technical fall score), but combat could be prolonged on the ground with grappling techniques (Boguszewski, 2011) if the score is something less than ippon. In standing or groundwork combat, ippon can occur because of a throw, hold-down, arm lock or strangulation technique (Miarka et al., 2016b).

The connection of sequential actions during judo combat and critical indicators, such as approach and gripping moments, represents the main aspects of attacking systems applied by judo athletes (Calmet et al., 2010). Despite the performance-oriented sports context, pacing is part of grappling sports and allows for the regulation of exercise intensity throughout a bout for the purpose of maintaining internal homeostasis (Smits et al., 2014) and/or to avoid early exhaustion (Baron et al., 2009). Studies on EP ratios in judo are rare, but this kind of research could improve training with specific exercises and EP ratio simulations (Miarka et al., 2016a). It is very difficult to investigate open task modalities, such as judo, because pacing and decision making studies have to include a sequential combination of circumstantial aspects of the championships with a combination of interoceptive (i.e. physiological, psychological and/or technical analysis) and exteroceptive (i.e. environmental) factors (Tomazini et al., 2015). In sports, many studies have shown how self-paced performances and pacing are related (Smits et al., 2014), and how pacing strategies can be predicted based on theoretical modeling (Baron et al., 2009; El-Komsan and El-Gebaly, 2010). It has been found that athletes tend to self-select strategies closely related to their disposition during natural interactive behavior and decision-making (Baron et al., 2009). For instance, findings from a recent investigation showed the same self-select technical-tactical systems during approach and gripping states between winning and losing male halfmiddleweight athletes during high-level judo competition (Miarka et al., 2016b).

Regarding decision-making, it has been defined as the capability of individuals to select functional actions to achieve a specific task goal from a number of action possibilities (Baron et al., 2009; El-Komsan and El-Gebaly, 2010). During the EP ratio, action selection is an important component in the process of decision-making (Miarka et al., 2016b), as it is associated with a possible consequent reaction of the opponent (Boguszewski, 2011; Lech et al., 2015; Miarka et al., 2016b). In addition, flexibility of motor control relies on anticipation of subsequent events as well as concurrent and quick decision making to spatiotemporal changes (Boguszewski, 2011; Lech et al., 2015). Previous research displayed specific circumstantial observations, which affected judo performance and determined excellence, such as the correlation between approach and gripping (Calmet et al., 2010; Courel et al., 2014), effective attacks and their orientations (Heinisch et al., 2013; Miarka et al., 2014; Sterkowicz et al., 2010, 2013), gripping patterns and throwing side analysis (Courel et al., 2014) as well as effect of penalties on subsequent attack effectiveness (Escobar-Molina et al., 2014; Kajmovic and Radjo, 2014).

A Markov process consists of a statistical analysis that could show how the decision changes among a series of situations in continuous analysis (Miarka et al., 2015). It is useful for studying a wide range of optimization problems solved via dynamic programming to improve the decisionmaking accuracy in reactive actions (Henry et al., 2013). Several stochastic models have been deployed within performance analysis of team sports (Gray and Gray, 1997), and studies made use of probabilities models with the Markov chain while concentrating on the calculation of success predictions and decision making was incorporated into the stochastic 
models (Barnett and Pollard, 2011). In these studies, the Markov decision process was applied to describe and predict playing profiles or patterns (Miarka et al., 2016b), and in order to determine the performance relevance of tactical behavior patterns, rather than the frequency of their use (Miarka et al., 2016b). In this sense, preceding research described a dynamic programming model, which estimated probabilities results of each NCAA Basketball team and suggested a strategy that could be used to maximize one's pool score by Markov Chains (Gray and Gray, 1997). Frequency and duration of actions in judo combats, knowledge of the end point, and the physical sensations of effort and fatigue have all been associated with adequate perception and timing to execute an action (Miarka et al., 2015), and their integration seems to guide appropriate pacing in open task sports, as previous research has indicated (Swart et al., 2012).

Based on these statements, a wellestablished experimental paradigm to investigate pacing and decision making, according to combat phases (states) during sequential actions as precisely as possible, requires a large database able to show sequential actions and decisions (Barnett and Pollard, 2011; Gray and Gray, 1997; Swart et al., 2012). This research provides an overview of how decision-making and pacing strategy are treated in the judo EP ratio within combat regulation and pacing during different championships. To identify underlying mechanisms that are relevant in the regulation of judo athlete's action intensity, the current investigation aimed to compare both pacing strategy and decision making used in each judo EP ratio by the context and regulation over the championship phases of Olympic and nonOlympic tournaments.

\section{Methods}

\section{Participants}

The study sample was formed based on the athlete's performance during international competitions and 2.316 male combats in 2011 and 2012 from all seven-weight categories were analyzed. Of these, 53.403 sequential actions were examined from 774 judo matches (611 from nonOlympic competitions (eliminatory $\mathrm{n}=330$, quarter-finals $\mathrm{n}=60$, semi-final $\mathrm{n}=88$, repechage $\mathrm{n}=21$, third place playoff $\mathrm{n}=26$, final $\mathrm{n}=79$ ) and
163 from the Olympic Games (eliminatory $n=71$, quarter-finals $\mathrm{n}=13$, semi-final $\mathrm{n}=26$, repechage $\mathrm{n}=20$, third place playoff $\mathrm{n}=24$, final $\mathrm{n}=14)$ ) in 2011 and 2012 by 22 men, from each weight category, ranked as elite in the sport of judo, and qualified for the 2012 Olympic Games.

To guarantee ecological validity and facility to acquire high-level performances, these databases were documented by different cameras, which had as criteria the standard definition of $480 / 60 \mathrm{i}$ in $60 \mathrm{~Hz}$, following preceding protocols (Miarka et al., 2017), from 36 international competitions with their respective venues and year, namely: the Olympic Games (London, 2012), World Championship (Paris, 2011), two editions of World Masters (Almaty, 2012; Baku, 2011), five Grand Slams (Paris, 2011 and 2012; Tokyo, 2011; Rio de Janeiro, 2011 and Moscow, 2011), five Grand Prix's (Düsseldorf, 2011 and 2012; Qingdao, 2011; Amsterdam, 2011; Abu Dhabi, 2011), three Continental Competitions (Asian, Uzbekistan, 2012; American, Montreal, 2012, and; European, Chelyabinsk, 2012) and 19 World Cups (Prague, 2012 and 2011; Oberwart, 2012 and 2011; Bucharest, 2012 and 2011; Jeju, 2012; Madrid, 2012 and 2011; Tbilisi, 2012 and 2011; Warsaw, 2011, Tallinn, 2012, Miami, 2012, San Salvador, 2012, Apia, 2012, Buenos Aires, 2012, Lisbon, 2012 and Sofia, 2012), according to the International Judo Federation's calendar and data (IJF, 2012). The free computer version of VirtualDub Program 1.8.6 was used to fragment and edit images and Frami-software 1.2.0 (Miarka et al., 2011) was used to analyze the sequential actions. The study was approved by the local Ethics and Research Committee, following resolution 196/96 of the National Health Council.

\section{Experimental design}

This study addressed the following aspects: analysis and modeling of self-paced combat states during judo EP ratios. The study design was divided into three stages. Firstly, all the self-paced states were identified and they were combined with decision-making variables, regarding unpredictable and efficiency variables in EP ratios of judo combats, which were incorporated in a conceptual model of pacing and decision-making. Afterwards, intra and interexpert validation of the model was conducted with a randomized selection of the combat records. Lastly, statistical analysis of self-pacing and frequencies during EP ratios of judo bouts was 
conducted with Markovian Processes. Markovian Processes were applied to observe the probability of the sequential decision and consequent combinations between states.

\section{Self-pacing in the judo EP ratio}

A sequential analysis of combat states was performed according to each frequency of occurrence and time, then normalized and presented by the percentage of the EP ratio. The analysis of each EP ratio was defined in periods of the states: approach ( $\Delta$ approach), gripping $(\Delta$ gripping), attack ( $\Delta$ attack $)$, groundwork $(\Delta$ groundwork) and pause ( $\Delta$ pause), adapting previous reports (Tomazini et al., 2015). Whereupon, the approach was defined as the time between the signal from the referee announcing the beginning of combat ("hajime") and the execution of the grip (kumi-kata). During this period, athletes do not have any physical contact between them (Calmet et al., 2010). Gripping was defined as the time between the accomplishment of the grip (kumi-kata) and the breaking of contact with the opponent judogi (Miarka et al., 2011). Attack was defined as the initial breaking balance of the opponent (kuzushi) and its orientation, and the preparatory moves of the body, especially of the feet, made prior to the attack (tsukuri) and the final movement, with an attempt to throw the opponent (kake) (Miarka et al., 2015). Defense (tae-sabaki) was defined as initial or preparatory moves of the body, especially of the feet, made to escape the opponent's attack and the final movement (Boguszewski, 2011). The groundwork combat was defined as the period where one or both fighters executed groundwork techniques (ne-waza), according to previous protocols (Miarka et al., 2016b). The pause was defined as the period between the signal for combat interruption ("matte") and the signal to restart the combat (voice command "hajime"). The present study did not observe the "sono-mama" and "yoshi" commands halting and restarting the fight, which would also have been computed as recovery if they had had occurred (Miarka et al., 2016b). Lastly, combat was defined as the period between the order from the referee to initiate the fight ("hajime"), the order to stop the fight ("matte"), and the order to finish the fight ("soremade"), according to previous protocols (Miarka et al., 2016b).

To guarantee internal validity and verify the objectivity of the analysis, the reliability measures were assessed through intra-observer and inter-observer testing procedures (Miarka et al., 2015). The variables showed agreement classified as 'Almost Perfect' for Kappa values, with a range of agreement between 0.84 and 1.00 for all analyzed measures - both assessed through intra-observer and inter-observer tests previously described (Miarka et al., 2015).

\section{Combat state and decision-making assessment}

The Markov process describes how an athlete makes decision to move between a series of EP ratio states in continuous time (Jackson, 2011). Suppose an athlete is in state $S(t)$ at time $t$. The movement on the set of combat states is governed by transition intensities denoted by $q_{r s}(t, z(t))$, which represents the instantaneous risk of moving from state from $r$ to state $s, s \neq r$ :

$q_{r s}(t, z(t))=\lim _{\delta t \rightarrow 0} \frac{P(S(t+\delta t)=s \mid S(t)=r)}{\delta t}$.

These may depend on time $t$, or, more generally, also on a set of individual-level or timedependent explanatory variables $z(t)$, such as tournament phases and competition (Jackson, 2011).

The $q_{r s}$ forms an $R x R$ matrix $Q$ of which rows sum to zero, so that the diagonal entries are defined by:

$q_{r r}=-\sum_{s \neq r} q_{r s}$.

Fitting multi-state models for panel data generally relies on the Markov assumption that future evolution only depends on the current selfpaced state, which means that the next movement depends on the preceding movements. In a timehomogeneous Markov model, in which $q_{r s}$ is also independent of $t$, the sojourn time in each state $r$ is exponentially-distributed with mean $-1 / q_{r r}$. The probability that an individual in state $r$ moves next to state $S$ is $p_{r s}=-q_{r s} / q_{r r}$ (Jackson, 2011).

Following the state sequences in the EP ratio, the system begins in an initial state "approach" before passing to the next state, in our case "gripping" and "attack", which is described in four orientations. By defining these situations for each athlete, the alternating sequence of states in the combat allows the interaction between the variables to be illustrated or modeled. In the next 
step, the transition probability between the states can be transformed into a dimensional transition matrix (Jackson, 2011). Each element of this matrix has the property $p_{r s} \geq 0$ and the line sum is equal to 1 . In this way, the transition matrix provides a true result of the interactive combat process, and provides an insight into the decision made to choose the self-paced states used during the EP ratios (Jackson, 2011). On the basis of the transition matrix, the Markov process is a discrete time stochastic control process where the decision maker may choose any self-paced state described in the protocol purposed and it can be defined as the transition probability between two states, which will be demonstrated in the results. All analyses were conducted using the msn package (Jackson, 2011) for R Computational Program 3.0.2 (R Core Team, 2013) and the significance level of $p$ $\leq 0.05$ was used.

\section{Statistical Analysis}

Descriptive data were presented as mean (SD). For the frequencies, Poisson regression analysis was conducted in order to compare groups and ANOVA two-way was used to compare measured continuous time variables across states. When differences were detected, the post hoc Bonferroni test was used to identify specific differences between groups. The maximum likelihood estimate (B) and the Wald Chi-square (WC) were examined for the frequencies and, for the continuous time the Eta squared $\left(\eta^{2}\right)$ was calculated and they were designed for all variance analyses, with the significance level of $p \leq 0.05$. For comparisons, the SPSS statistical package (version 20.0, Chicago, IL, USA) was used.

\section{Results}

Table 1 shows the descriptive analysis of self-paced states by tournament phases of Olympic and non-Olympic judo combats, in percentages normalized by the EP ratio.

Statistical analysis demonstrated differences among tournament phases of the Olympic and non-Olympic Games in the approach percentage $\left(F_{11,773}=3.494, p<0.001, \eta^{2}=0.048\right)$, where the eliminatory phase of Olympic bouts demonstrated a higher percentage than semi-final $(p=0.003)$ and third place playoff $(p=0.032)$ from non-Olympic bouts. Also, statistical analysis showed differences among tournament phases in the pause percentage $\left(\mathrm{F}_{11,773}=1.811, p=0.048, \eta^{2}=\right.$ 0.026), where Olympic Games semi-final bouts presented lower values than final bouts $(p=0.032)$ of the non-Olympic Games. Table 2 presents the frequency analysis of each state during the tournament phases of Olympic and non-Olympic judo bouts, by the EP ratio.

The comparison indicated differences among tournament phases of the Olympic and non-Olympic Games in approach frequencies $(\mathrm{B}=$ 2.243, $p=0.045, \mathrm{WC}=20.050, \mathrm{df}=11$ ), where finals of non-Olympic bouts showed higher values than eliminatory $(p<0.001)$, quarter-finals $(p=0.039)$, semi-final $(p<0.001)$ and repechage $(p=0.005)$ of non-Olympic bouts, and final bouts of nonOlympic Games were higher than eliminatory $(p=$ $0.004)$, quarter-finals $(p=0.030)$ and repechage $(p=$ 0.030) of the Olympic Games.

Effects were observed when comparing tournament phases of the Olympic and nonOlympic Games in attack frequencies $(B=2.444, p$ $=0.005, \mathrm{WC}=26.560, \mathrm{df}=11)$, where third place playoff bouts of the Olympic Games showed higher values than eliminatory $(p=0.006)$, quarterfinals $(p=0.008)$, semi-final $(p=0.029)$, repechage $(p=0.002)$, third place playoff $(p=0.047)$ and finals $(p=0.005)$ of non-Olympic combats; repechage of Olympic combats showed a higher number of attacks than eliminatory $(p=0.010)$, quarter-finals $(p=0.012)$, semi-final $(p=0.038)$, repechage $(p=$ $0.003)$ and final $(p=0.008)$ of the non-Olympic Games; the third place playoff of the Olympic Games showed higher frequencies of attacks than repechage ( $p=0.022)$ of non-Olympic bouts, as the repechage of the Olympic Games showed a higher number of attacks by the EP ratio than eliminatory $(p=0.025)$, quarter-final $(p=0.025)$, repechage $(p=$ $0.006)$ and final $(p=0.020)$ of non-Olympic bouts, and the eliminatory from the Olympic Games had a higher number of attacks than the repechage $(p=$ 0.34) of non-Olympic bouts.

The analysis showed differences between EP ratios of bouts in Olympic and non-Olympic tournaments $(\mathrm{B}=2.243, p=0.045, \mathrm{WC}=20.050, \mathrm{df}=$ $11)$, where eliminatory phases of non-Olympic bouts showed higher values than quarter-finals $(p$ $=0.024$ ) of non-Olympic bouts, and lower values than repechage bouts $(p=0.10)$ of the Olympic Games; while the quarter-finals of non-Olympic bouts presented lower EP ratios than semi-final ( $p$ $=0.014)$ and final $(p<0.001)$ bouts from non- 
Olympic bouts, and lower than third place playoff bouts from the Olympic Games $(p=0.005)$; whereas bouts from the finals of non-Olympic tournaments presented lower values of EP ratios than semi-final Olympic Games bouts $(p<0.001)$, and; semi-final Olympic Games bouts presented higher frequencies of the EP ratio than eliminatory $(p=0.010)$ bouts and lower values than bouts from repechage $(p=0.020)$ and third place playoffs $(p=$ 0.002 ) of the Olympic Games. Figure 1 shows descriptive analysis of states self-paced time by the championship phase in Olympic and non-Olympic judo combats, in seconds by the EP ratio.

\section{Table 1}

Descriptive analysis of states self-paced by EP ratio during tournament phases

of Olympic and non-Olympic judo combats, in percentage of total time normalized and presented as mean $\pm S D$.

\begin{tabular}{|c|c|c|c|c|c|c|}
\hline $\begin{array}{c}\text { Tournament } \\
\text { phase }\end{array}$ & $\Delta$ Approach & $\Delta$ Gripping & $\Delta$ Attack & $\begin{array}{c}\Delta \\
\text { Defense }\end{array}$ & $\Delta$ Groundwork & $\Delta$ Pause $^{*}$ \\
\hline \multicolumn{7}{|c|}{ Non-Olympic Games } \\
\hline Eliminatory & $26 \pm 10 \%$ & $19 \pm 10 \%$ & $7 \pm 4 \%$ & $15 \pm 11 \%$ & $9 \pm 8 \%$ & $21 \pm 13 \%$ \\
\hline Quarter-final & $26 \pm 9 \%$ & $19 \pm 9 \%$ & $7 \pm 4 \%$ & $15 \pm 8 \%$ & $8 \pm 5 \%$ & $26 \pm 24 \%$ \\
\hline Semi-final & $24 \pm 9 \%$ & $18 \pm 12 \%$ & $8 \pm 4 \%$ & $17 \pm 10 \%$ & $8 \pm 6 \%$ & $20 \pm 14 \%{ }^{\circledR}$ \\
\hline Repechage & $22 \pm 9 \%$ & $18 \pm 10 \%$ & $9 \pm 4 \%$ & $15 \pm 11 \%$ & $8 \pm 6 \%$ & $21 \pm 10 \%$ \\
\hline $\begin{array}{l}\text { Third place } \\
\text { playoff }\end{array}$ & $23 \pm 9 \%$ & $16 \pm 8 \%$ & $9 \pm 5 \%$ & $14 \pm 12 \%$ & $8 \pm 6 \%$ & $27 \pm 36 \%$ \\
\hline Final & $25 \pm 13 \%$ & $19 \pm 10 \%$ & $7 \pm 4 \%$ & $15 \pm 12 \%$ & $9 \pm 10 \%$ & $17 \pm 13 \%$ \\
\hline \multicolumn{7}{|c|}{ Olympic Games } \\
\hline Eliminatory & $30 \pm 11 \%$ & $19 \pm 9 \%$ & $6 \pm 3 \%$ & $14 \pm 9 \%$ & $10 \pm 8 \%$ & $22 \pm 15 \%$ \\
\hline Quarter-final & $32 \pm 12 \%$ & $17 \pm 6 \%$ & $5 \pm 4 \%$ & $20 \pm 10 \%$ & $7 \pm 2 \%$ & $22 \pm 10 \%$ \\
\hline Semi-final & $31 \pm 8 \%$ & $19 \pm 6 \%$ & $6 \pm 3 \%$ & $14 \pm 9 \%$ & $9 \pm 7 \%$ & $25 \pm 9 \%$ \\
\hline Repechage & $27 \pm 7 \%$ & $20 \pm 14 \%$ & $7 \pm 3 \%$ & $13 \pm 4 \%$ & $8 \pm 4 \%$ & $21 \pm 22 \%$ \\
\hline $\begin{array}{l}\text { Third place } \\
\text { playoff }\end{array}$ & $30 \pm 9 \%$ & $17 \pm 6 \%$ & $6 \pm 3 \%$ & $16 \pm 7 \%$ & $9 \pm 5 \%$ & $15 \pm 8 \%$ \\
\hline Final & $24 \pm 8 \%$ & $21 \pm 5 \%$ & $7 \pm 3 \%$ & $19 \pm 12 \%$ & $5 \pm 4 \%$ & $22 \pm 14 \%$ \\
\hline \multicolumn{7}{|c|}{$\begin{array}{c}\text { * Pause percentage / full time (combat plus pause moments); \# different from semi-final } \\
\text { and third place playoff from non-Olympic combats; }{ }^{\circledR} \text { different from final } \\
\text { non-Olympic combats, } p<0.05 \text { for all analyses }\end{array}$} \\
\hline
\end{tabular}


Table 2

Descriptive analysis of states by the EP ratio during tournament phases of Olympic and non-Olympic judo combats, in frequency and presented as mean $\pm S D$.

\begin{tabular}{|c|c|c|c|c|c|c|}
\hline $\begin{array}{c}\text { Tournament } \\
\text { phase }\end{array}$ & Approach & Gripping & Attack & Defense & Groundwork & EP ratio* \\
\hline \multicolumn{7}{|c|}{ Non-Olympic Games } \\
\hline Eliminatory & $2 \pm 1$ & $1 \pm 0.2$ & $2.2 \pm 1.4$ & $0.4 \pm 0.4$ & $2 \pm 1$ & $9 \pm 6^{\beta}$ \\
\hline Quarter- final & $2 \pm 1$ & $1 \pm 0.1$ & $2.1 \pm 1.2$ & $0.5 \pm 0.3$ & $2 \pm 1$ & $9 \pm 5^{\pi}$ \\
\hline Semi-final & $2 \pm 1$ & $1 \pm 0.2$ & $2.3 \pm 1.4$ & $0.5 \pm 0.5$ & $2 \pm 1$ & $10 \pm 6$ \\
\hline Repechage & $2 \pm 1$ & $1 \pm 0.1$ & $1.7 \pm 1.0$ & $0.3 \pm 0.3$ & $2 \pm 1$ & $10 \pm 6$ \\
\hline $\begin{array}{l}\text { Third place } \\
\text { playoff }\end{array}$ & $2 \pm 1$ & $1 \pm 0.1$ & $2.1 \pm 1.5$ & $0.4 \pm 0.3$ & $2 \pm 1$ & $9 \pm 6$ \\
\hline Final & $2 \pm 1^{\#}$ & $1 \pm 0.3$ & $2.1 \pm 1.3$ & $0.5 \pm 0.4$ & $2 \pm 1$ & $9 \pm 6$ \\
\hline \multicolumn{7}{|c|}{ Olympic Games } \\
\hline Eliminatory & $2 \pm 1$ & $1 \pm 0.3$ & $2.4 \pm 1.5 \%$ & $0.5 \pm 0.4$ & $2 \pm 1$ & $9 \pm 6$ \\
\hline Quarter-final & $2 \pm 0$ & $1 \pm 0.0$ & $3.0 \pm 0.9$ & $0.5 \pm 0.3$ & $2 \pm 1$ & $14 \pm 5$ \\
\hline Semi-final & $2 \pm 1$ & $1 \pm 0.1$ & $2.6 \pm 1.2$ & $0.6 \pm 0.3$ & $2 \pm 1$ & $12 \pm 5^{\Omega}$ \\
\hline Repechage & $2 \pm 1$ & $1 \pm 0.2$ & $3.0 \pm 1.1^{¥}$ & $0.7 \pm 0.3$ & $2 \pm 1$ & $13 \pm 6$ \\
\hline $\begin{array}{l}\text { Third place } \\
\text { playoff }\end{array}$ & $2 \pm 2$ & $1 \pm 0.2$ & $3.0 \pm 1.8^{¥}$ & $0.7 \pm 0.4$ & $2 \pm 1$ & $12 \pm 8$ \\
\hline Final & $2 \pm 0^{\circledR}$ & $1 \pm 0.1$ & $2.4 \pm 1.1$ & $0.5 \pm 0.2$ & $2 \pm 1$ & $11 \pm 5$ \\
\hline
\end{tabular}

${ }^{*} E: P$ ratio frequencies by each combat; \# different from eliminatory, quarter finals, semi-final and repechage of non-Olympic combats; $®$ different from eliminatory, quarter finals and repechage phase from Olympic Games; $¥$ different from all tournament phases from the other Competition group; = ж) different from repechage of non-Olympic combats; $\pi$ different from eliminatory, semi-finals, finals of non-Olympic combats, and from third place playoff of Olympic Games; $\Omega$ different from eliminatory, repechage and third place playoff from Olympic Combats;

$\boldsymbol{\beta}$ different from repechage of Olympic Games, $p<0.05$ for all analyses 
Table 3

Descriptive analysis of attack orientations by the EP ratio during tournament phases, in percentage of attacks and presented as mean $\pm S D$.

\begin{tabular}{|c|c|c|c|c|}
\hline Tournament phase & Frontal attack & Right attack & Rear attack & Left attack \\
\hline \multicolumn{5}{|c|}{ Non-Olympic Games } \\
\hline Eliminatory & $11 \pm 18 \%$ & $20 \pm 25 \%$ & $28 \pm 30 \%$ & $14 \pm 19 \%$ \\
\hline Quarterfinals & $12 \pm 19 \%$ & $19 \pm 23 \%$ & $27 \pm 37 \%$ & $14 \pm 22 \%$ \\
\hline Semi-final & $12 \pm 20 \%$ & $18 \pm 25 \%$ & $22 \pm 25 \%$ & $14 \pm 20 \%$ \\
\hline Repechage & $16 \pm 24 \% \circledast$ & $16 \pm 14 \%$ ж & $23 \pm 34 \%$ & $7 \pm 10 \%$ \\
\hline Third place playoff & $16 \pm 16 \%$ & $27 \pm 28 \%$ & $44 \pm 71 \%$ & $13 \pm 17 \%$ \\
\hline Final & $9 \pm 16 \%$ & $17 \pm 28 \%$ & $23 \pm 24 \%$ & $18 \pm 27 \%$ \\
\hline \multicolumn{5}{|c|}{ Olympic Games } \\
\hline Eliminatory & $11 \pm 23 \%$ & $18 \pm 23 \%$ & $29 \pm 29 \%$ & $14 \pm 19 \%$ \\
\hline Quarterfinals & $8 \pm 9 \%$ & $19 \pm 28 \%$ & $23 \pm 13 \%$ & $13 \pm 22 \%$ \\
\hline Semi-final & $15 \pm 25 \%$ & $12 \pm 16 \%$ & $23 \pm 22 \%$ & $9 \pm 13 \%$ \\
\hline Repechage & $10 \pm 14 \%$ & $9 \pm 15 \%$ b & $31 \pm 31 \%$ & $16 \pm 15 \%$ \\
\hline Third place playoff & $11 \pm 17 \%$ & $17 \pm 18 \%$ & $21 \pm 25 \%$ & $28 \pm 50 \%$ \\
\hline Final & $5 \pm 11 \%$ & $17 \pm 13 \%$ & $23 \pm 16 \%$ & $7 \pm 11 \%$ \\
\hline
\end{tabular}

${ }^{\circledR}$ different from quarterfinals and repechage of the Olympic Games;

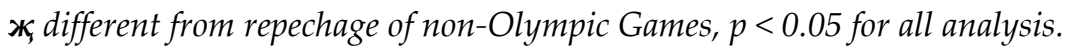




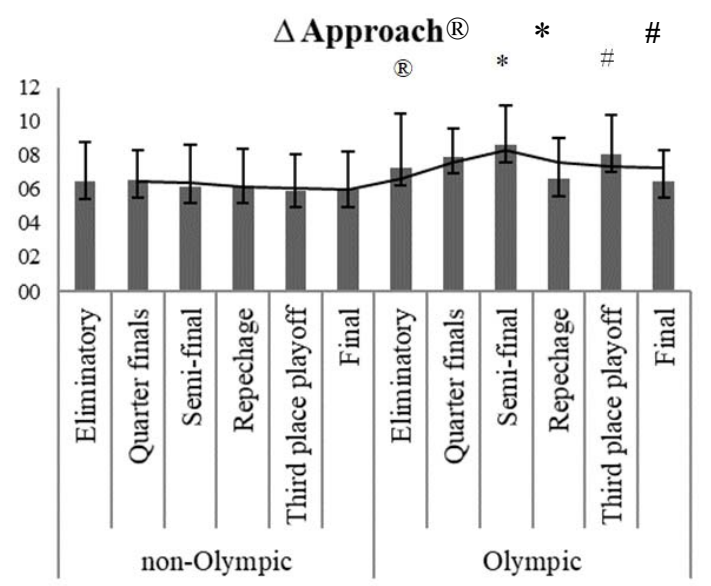

$\Delta$ Attack

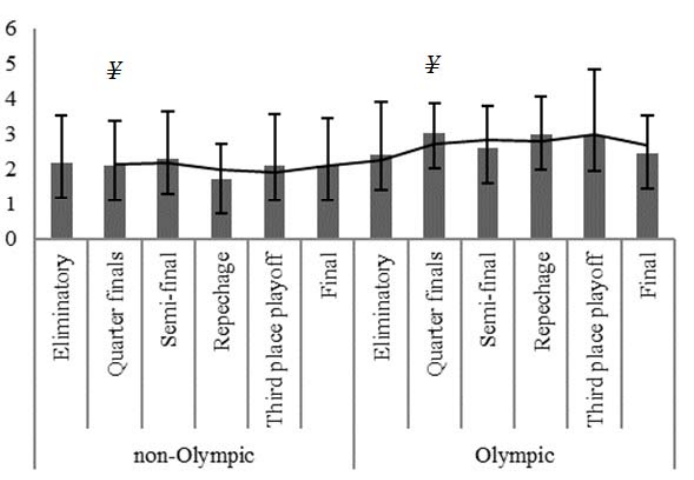

$\Delta$ Groundwork

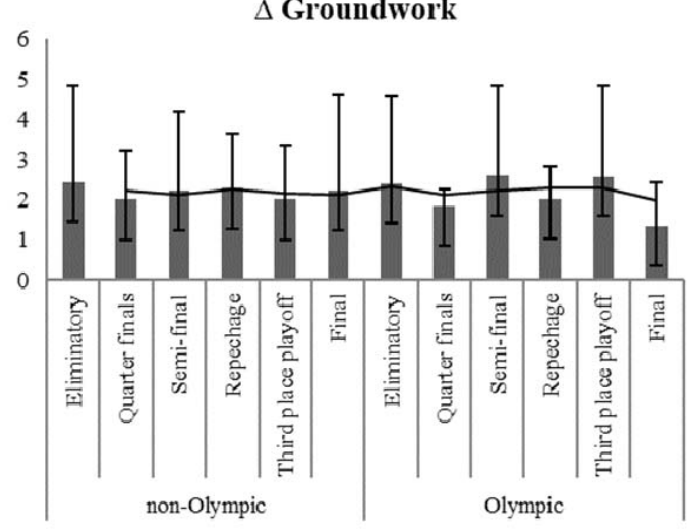

$\Delta$ Gripping

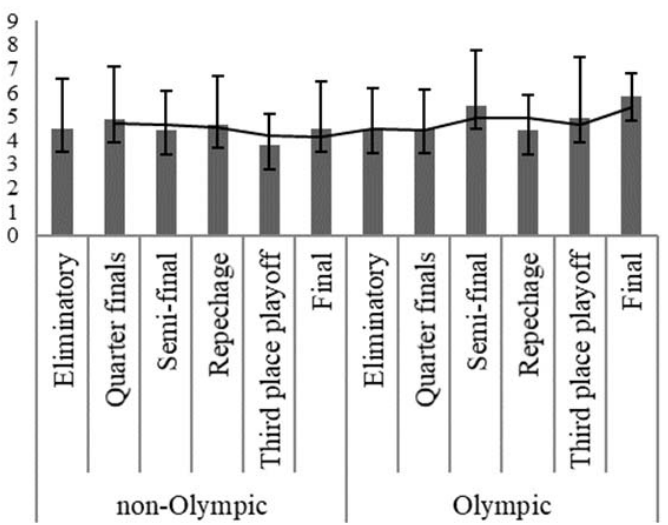

$\Delta$ Defense
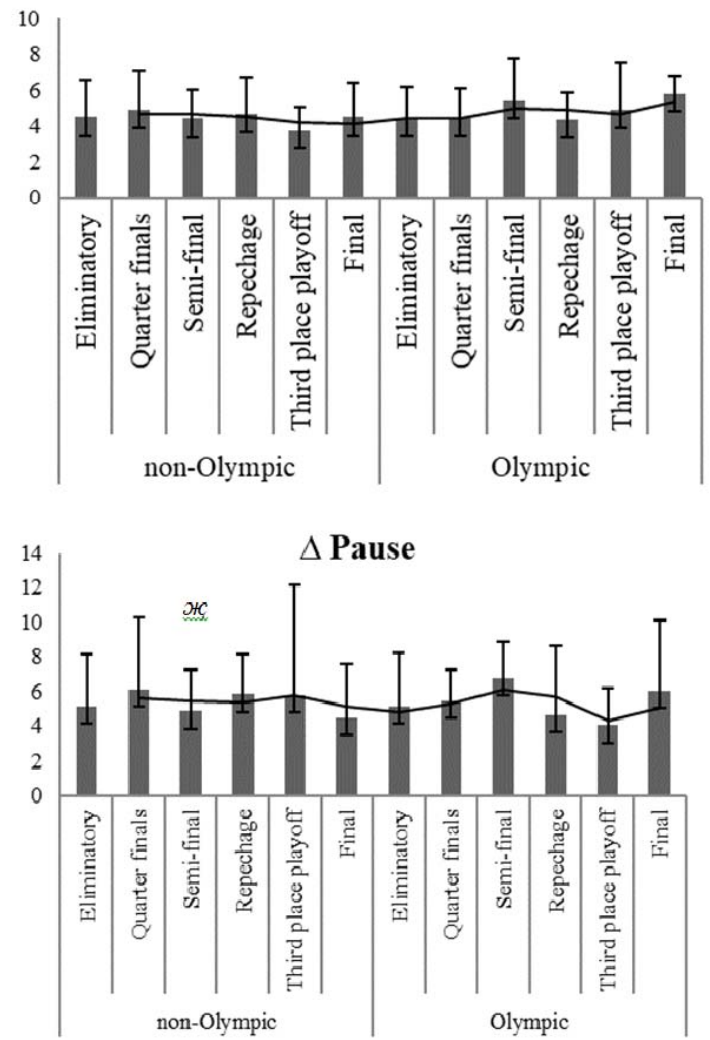

Figure 1

States self-paced by the EP ratio during championship phases in judo combats, in seconds.

Note: * different from eliminatory, quarter finals, semi-final, repechage, third place playoff, and final of non-Olympic combats; " different from semi-final and finals of non-Olympic combats;

${ }^{\circledR}$ different from final phases of non-Olympic combats; $¥$ different from eliminatory phase

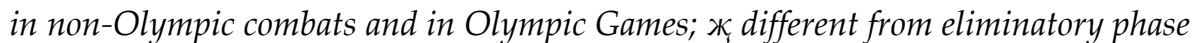
of Olympic Games, $p<0.05$ for all analyses 
The analysis showed differences among tournament phases of the Olympic and nonOlympic Games in approach time $\left(\mathrm{F}_{11,773}=4.497, p\right.$ $<0.001, \eta^{2}=0.061$ ), where the semi-final of Olympic combats demonstrated longer periods than eliminatory $(p<0.001)$, quarter-final $(p=0.013)$, semi-final $(p<0.001)$, repechage $(p=0.024)$, third place playoff $(p=0.022)$, and final $(p<0.001)$ of nonOlympic bouts; the third place playoff of the Olympic Games showed longer periods of approach than semi-final and finals of nonOlympic bouts, and the eliminatory of Olympic combats demonstrated longer periods than final phases of non-Olympic matches $(p=0.034)$. Effects of tournament phases in Olympic and nonOlympic bouts were observed in attack state time $\left(F_{11,773}=1.926, p=0.033, \eta^{2}=0.027\right)$, where the quarter-final demonstrated a longer time than the eliminatory phase in non-Olympic bouts $(p=0.36)$ and in the Olympic Games ( $p=0.016)$. In addition, statistical analysis showed differences among groups in the pause state period $\left(\mathrm{F}_{11,773}=2.170, p=\right.$ $0.014, \eta^{2}=0.030, d f=11$ ), where Olympic semi-final bouts showed longer times than eliminatory phases $(p=0.048)$. Table 3 shows descriptive analysis of attack orientations by tournament phases of Olympic and non-Olympic judo bouts, in the percentage of attacks used in the EP ratio.

Statistical analysis showed differences among tournament phases of the Olympic and non-Olympic Games when analyzing frontal attacks $\left(\mathrm{F}_{11,773}=1.930, p=0.033, \eta^{2}=0.027\right)$, where the repechage from non-Olympic bouts showed a higher percentage of frontal attacks than quarterfinal bouts $(p=0.016)$ and repechage $(p=0.035)$ phases of the Olympic Games. Effects among tournament phases of the Olympic and nonOlympic Games were observed when compared to attacks to the right side $\left(\mathrm{F}_{11,773}=2.019, p=0.024, \eta^{2}\right.$ $=0.028)$, where the repechage of the non-Olympic Games showed a lower percentage than repechage $(p=0.034)$ of the Olympic Games.

Regarding sequential states in the decisionmaking process required during combat, the athlete must present a high level of awareness and have the opportunity to choose or create several possible technical actions. About fifty-three thousand sequential actions were observed to compare the groups and no effects were verified among the probabilities of combinations observed between self-paced states in EP ratios, which were used in different tournament phases of nonOlympic and Olympic combats. The main descriptive results indicated the following sequential combinations: the approach state had the highest probability to occur before a new attempt to approach (86\%) followed by gripping $(10 \%)$, defense $(1 \%)$ and pause $(1 \%)$. Furthermore, the gripping state had the highest probability to occur before a new gripping configuration (85\%), defense $(3 \%)$ or approach $(3 \%)$, attack to the right $(2 \%)$, groundwork $(2 \%)$ and pause $(2 \%)$; moreover, attacks to the front revealed a stronger probability to be combined with an attack to the same orientation $(43 \%)$, gripping (24\%), groundwork $(14 \%)$, and pause $(7 \%)$. In addition, attacks to the rear had the highest probability to occur before a new condition or attack to the same orientation $(52 \%)$, groundwork $(22 \%)$, gripping $(11 \%)$ and pause $(9 \%)$. Attacks to the right had the highest probability to occur before a new condition or attack attempt to the same orientation $(47 \%)$, groundwork $(21 \%)$, gripping $(16 \%)$ and pause $(9 \%)$. On the other hand, attacks to the left obtained the highest probability of transition with a new condition or attempt to the left orientation (33\%), gripping $(32 \%)$, groundwork $(15 \%)$ and pause $(8 \%)$.

\section{Discussion}

Previous judo studies have contributed to the determination of judo athlete's pacing strategy during tournament phases (Calmet et al., 2010; Courel et al., 2014; Escobar-Molina et al., 2014; Miarka et al., 2016a; Slimani et al., 2016). This article sought to understand the mechanisms involved in pacing strategy and decision-making used in each self-paced EP ratio by the context and regulation over the judo championship phases of the Olympic and non-Olympic Games. The main results indicated an increase in combat intensity and frequency of attacks in the final bouts of the Olympic Games, especially in the semifinals. However, the approach also increased in the final combats, probably indicating the need for a longer waiting time to apply the planned tactics. Our results seem to associate that pacing with interoceptive and exteroceptive circumstantial factors, as previous studies suggested (Smits et al., 2014; Tomazini et al., 2015), which are integrated in appropriate combat state self-regulation by Olympic athletes, especially finalists. Furthermore, 
an ecological approach to pacing and decisionmaking was considered and no effects were observed when compared to the probability of transitions between self-paced states during the decision-making process in the tournament phases. Interestingly, this showed that the decisions in high-level athletes were very similar, while the duration and frequency of the actions resulting from these decisions presented significant differences, particularly in the approach, pause attacks and their orientations.

A central notion in the present approach are self-paced states of the EP judo ratio during tournament phases of international competitions. Athletes presented similar $\Delta$ gripping, $\Delta$ defense and $\Delta$ groundwork between tournament phases, and this observation is of physiological significance as it indicates that the EP ratio intensity during tournament phases was selfregulated relatively to the athlete's capability near the final. Previously weight categories were differentiated (Sterkowicz-Przybycien et al., 2017) and it needs to be considered in pacing strategies. A preceding study demonstrated differential effects by the weight category and sex divisions on phases of combat in elite judo athletes, with a greater focus on the heavyweight category (Sterkowicz-Przybycien et al., 2017). Also, a greater accumulated time in the approach and gripping phases for the middleweight category may reflect a specific pacing strategy for combat phases unique to this division and large effects among the sex and weight divisions were observed for the duration of the attack and defense phases within an individual combat sequence (Sterkowicz-Przybycien et al., 2017). A positive pacing strategy has been observed in all weight categories when examining the differences between tournament phases, reinforcing the notion that the finalist maintains a submaximal work rate in the same pattern until near the final, which suggests that the match is regulated in a complex self-selected manner using the pause and approach moments to recovery and to support subsequent gripping, attack/defense and groundwork moments (Branco et al., 2013).

In pacing studies perception is usually investigated by focusing on processes generally accepted to be affiliated to the perception, such as self-adjustments accompanying activity situations (El-Komsan and El-Gebaly, 2010; Tomazini et al., 2015). It is influenced by decision-making, which refers to the capability to select functional actions to achieve a specific task goal from a number of action possibilities (Miarka et al., 2016b). In the present study, a different representation emerged when the athlete was able to increase the attack rate, as occurred in the repechage and third place playoff; similarly, in the repechage the orientation to the right side had higher values than other tournament phases. There may be a centrally mediated mechanism to increase the offensive position during these tournament phases, or when athletes assume to have nothing to lose in the championship match, before the 'anticipated end of the tournament' (Baron et al., 2009; El-Komsan and El-Gebaly, 2010; Tomazini et al., 2015). Similar considerations were found in preceding reports with running race simulation, where athletes in the finals were able to determine the pace of their different championship phases (Swart et al., 2012; Tomazini et al., 2015).

During international tournaments in general, athletes compete multiple times towards a championship match. To control the number of times that athletes competed until at least the semifinal, present data used a high number of combats belonging to the same 22 ranked athletes. These athletes needed to score for the ranking to be placed among the top 7 of Olympic ranking events which ensured repeated measurements of the same athletes for the disputes carried out. The concern to score in the ranking may explain why the number of attacks increased in the quarterfinals, as well as the increase of the approach state, attempting to grip during the semifinal. These results are supported by previous findings, which did not identify differences between losers and winners, except in groundwork combat time (Miarka et al., 2016c).

Regarding the first situation in the EP ratio of judo combat, the approach state had a high probability to be sequenced by the gripping state, as with the pause and pause with score states. These results agree with previous studies that indicated the association between judo experiences with the long time spent in the approach state as a tactical element (Calmet et al., 2010; Courel et al., 2014). The present results showed that the approach state was longer in eliminatory, semifinal and third place playoff; at this time, tactical attempts to avoid the opponent's gripping control, trying to recognize weak points without gripping 
or without applying real attacks could induce penalty situations (Escobar-Molina et al., 2014), as it could interfere in subsequent attack effectiveness and in the outcome of the bout (Escobar-Molina et al., 2014). Present analysis of attacks was conducted and categorized into right- or left-side attacks; yet, left-dominant or right-dominant fighting stances need to be considered, as discriminant analysis demonstrated tactical elements of high-level athletes during the approach phase with stances opposite from their opponents (kenka-yotsu) (Miarka et al., 2016a). Tirp et al. (2017) examined the relative impact of a left-dominant vs. right-dominant fighting stance between and within competition levels. Left dominant judoka from all tournaments ranked 1st5th were over-represented compared to athletes who ranked 7th or worse at the German University Championship. Lateral differences in the fighting stance also differentiated between the tournament levels, with the highest percentage of judoka fighting with a left-dominant stance at the Olympic Games; the impact of a left-dominant fighting stance on competitive success differed within and between competition levels, however, no interaction between the fighting stance and rankings was revealed (Tirp et al., 2017). These results support the present finding that attacks to the left obtained the highest probability to be combined with penalty scores, followed by attacks to the front and the gripping state.

The present study agree with preceding reports, which showed no significant modifications in the transition probabilities between two female combat actions, but a pattern of self-adjustment in the attack rate emerged when the female athletes competed at the Olympic Games with an increase in the attack frequency coupled with a decrease in the attack duration (Miarka et al., 2016b). This change in response to the nature of the competition likely reflects a transition from the reactive mode to the anticipatory mode and is further supported by an increase in the frequency of multi-directional attacks (specifically to the rear and left orientations) (Miarka et al., 2015).

The pause state may be considered the time for strategic development, as athletes use this period for recovery and to receive feedback from their coaches (Miarka et al., 2014). The results from this study showed higher frequencies with a shorter pause time than previous studies (Branco et al., 2013; Escobar-Molina et al., 2014; Miarka et al., 2016a). This statement is supported by the fact that the 2008 Olympic Games in Beijing recorded 1.26 penalties/min and, in the 2012 Olympic Games, there was a considerable decrease in scores by penalties; with 0.44 penalties/min in a combat (Heinisch et al., 2013). Recently, the International Judo Federation (IJF, 2017) reduced the duration of contest and man and women are fighting for $4 \mathrm{~min}$ in the current Olympic cycle; the goal is to give priority to the attacks and to the realization of ippon (maximum score). This fact may interfere with the future frequency of attacks, and, consequently, in the pacing strategy of athletes, reducing approach and groundwork combat times.

Coaches and athletes can apply the results of the present study when establishing combat strategies during competitions. The analyzes indicated that the Olympic Games tended to be more competitive, presenting a higher intensity in the final combats. For judoka who are not yet ranked among the top 30 (qualifying zone for the Olympic Games), training strategies can be established focusing on technical-tactical actions and intensity of the Olympic Games, as such actions can increase success in classificatory competitions (Grand Prix, Grand Slam, etc.). Athletes classified for the Olympic Games can establish progressive combat strategies, since the final phases tend to be more intense and present a greater frequency of attacks.

\section{Conclusion}

The present study introduced a novel hypothesis inspired by an ecological approach to the integration of information in the context of pacing and decision making during judo tournament phases. To identify underlying mechanisms that are relevant in the regulation of judo athlete's action intensity, the current investigation considered self-paced states realized during the EP ratio in the context of the potential roles of perception and action in the regulation of bout intensity of Olympians. Results supported the hypothesis of self-regulation and showed no effects on the probability to combine the self-paced states during the tournament phases. This study revealed that decision making between Olympians was very similar, while the duration and frequency of the actions consequent of these decisions had 
differences, particularly, during the elimination and semifinal phases, where the approach and pause states expended more time. Also, in the repechage and the third place playoff the number of attacks and their orientations was higher than in other tournament phases. Each

state in the EP ratio information of the present study indicates the magnitude of the action during the tournament phases of Olympic and nonOlympic bouts, which can be used in judo physical training of athletes who have faced similar situations in judo tournaments, with repeated sessions similar to the EP ratio and its referential states.

\section{Acknowledgements}

Bianca Miarka would like to thank the FAPESP for the financial support (Grant \#2010/16494-4) and to CAPES (Grant PNPD) and Ciro Brito would like to thank the Brazilian Scholarship Program Ciência sem Fronteiras (Grant \#234243/2014-7).

\section{References}

Barnett T, Pollard GH. Devising new Australian rules football scoring systems. De Gruyter; 2011

Baron B, Moullan F, Deruelle F, Noakes TD. The role of emotions on pacing strategies and performance in middle and long duration sport events. Br J Sports Med 2009; 45(6): 511-517

Boguszewski D. Relationships between the rules and the way of struggle applied by top world male judoists. Arch Budo, 2011; 7(1): 27-32

Branco BH, Massuça LM, Andreato LV, Marinho BF, Miarka B, Monteiro L, Franchini E. Association between the rating perceived exertion, heart rate and blood lactate in successive judo fights (randori). Asian $\mathrm{J}$ Sports Med, 2013; 4(2): 125-130

Brito JC, Miarka B, Durana ALD, Fukuda D. Home Advantage in Judo: Analysis by the Combat Phase, Penalties and the Type of Attack. J Hum Kinet, 2017; 57: 235-243

Calmet M, Miarka B, Franchini E. Modeling of grasps in judo contests. Int J Perform Anal Sport, 2010; 10(3): 229240

Courel J, Franchini E, Femia P, Stankovic N, Escobar-Molina R. Effects of kumi-kata grip laterality and throwing side on attack effectiveness and combat result in elite judo athletes. Int J Perform Anal Sport, 2014; 14(1): 138-147

El-Komsan WA, El-Gebaly T. Time Management of the Training Process and its Relationship to the Quality of Decision Making to Coaches of Some Individual and Team Sports. World, 2010; 3(2): 90-99

Escobar-Molina R, Courel J, Franchini E, Femia P, Stankovic N. The impact of penalties on subsequent attack effectiveness and combat outcome among high elite judo competitors. Int J Perform Anal Sport, 2014; 14(3): 946-954

Franchini E, Artioli GG, Brito CJ. Judo combat: time-motion analysis and physiology. Int J Perform Anal Sport, 2013; 13(3): 624-641

Gołaś A , Maszczyk A, Zajac A, Mikolajec K, Stastny P. Optimizing Post Activation Potentiation for Explosive Activities in Competitive Sports. J Hum Kinet, 2016; 52 (1): 95-106

Gray PK, Gray SF. Testing market efficiency: Evidence from the NFL sports betting market. J Finance, 1997; 52(4): 1725-1737

Heinisch H, Oswald R, Ultsch D, Bazynski M, Birod M, Büsch D. Analysis of Olympic Games 2012 in Judo. Zeit Ang Training, 2013; 19(2): 121-150

Henry GJ, Dawson B, Lay BS, Young WB. Decision-making accuracy in reactive agility: Quantifying the cost of poor decisions. J Strength Cond Res, 2013; 27(11): 3190-3196

IJF. International Judo Federation Wide Consensus For the Adapted Rules of the Next Olympic Cycle. Available at: https://www.ijf.org/news/show/adapted-rules-of-the-next-olympic-cycle; accessed on 18.08.2017

Jackson CH. Multi-state models for panel data: the msm package for R. J Stat Software 2011; 38(8): 1-29

Kajmovic H, Radjo I. A Comparison of Gripping Configuration and Throwing Techniques Efficiency Index in Judo Between Male and Female Judoka During Bosnia and Herzegovina Senior State Championships. 
Int J Perform Anal Sport, 2014; 14(2): 620-634

Lech G, Chwała W, Ambroży T, Sterkowicz S. Muscle torque and its relation to technique, tactics, sports level and age group in judo contestants. J Hum Kinet, 2015; 45(1): 167-175

Miarka B, Branco BH, Vecchio FB, Camey S, Franchini E. Development and validation of a time-motion judo combat model based on the Markovian Processes. Int J Perform Anal Sport, 2015; 15(1): 315-331

Miarka B, Cury R, Julianetti R, Battazza R, Julio UF, Calmet M, Franchini E. A comparison of time-motion and technical-tactical variables between age groups of female judo matches. J Sports Sci, 2014; 32(16): 15291538

Miarka B, Fukuda DH, Del Vecchio FB, Franchini E. Discriminant analysis of technical-tactical actions in highlevel judo athletes. Int J Perform Anal Sport, 2016a; 16(1): 30-39

Miarka B, Fukuda DH, Heinisch H-D, Franchini E. Time-motion analysis and Decision Making in Female Judo Athletes during Victory or Defeat at Olympic and Non-Olympic Events: Are Combat Actions Really Unpredictable? Int J Perform Anal Sport, 2016b; 16(2): 442-463

Miarka B, Del Vecchio FB, Julianetti R, Cury R, Camey S, Franchini E. Time-motion and tactical analysis of Olympic judo fighters Int J Perform Anal Sport, 2016c; 16(2): 133-142

Miarka B, Hayashida CR, Julio UF, Calmet M, Franchini E. Objectivity of FRAMI-software for judo match analysis. Int J Perform Anal Sport, 2011; 11(2): 254-266

Miarka B, Sterkowicz-Przbycien K, Fukuda DH. Evaluation of Sex-Specific Movement Patterns in Judo Using Probabilistic Neural Networks. Motor Control, 2017; 21(4): 390-412

Ostrowski A, Strzała M, Stanula A, Juszkiewicz M, Pilch W, Maszczyk A. The Role of Training in the Development of Adaptive Mechanisms in Freedivers. J Hum Kinet, 2012; 32:197-210

Slimani M, Chaabene H, Miarka B, Chamari K. The Activity Profile of Elite Low-Kick Kickboxing Competition. Int J Sports Physiol Perform, 2017; 12(2): 182-189

Smits BL, Pepping G-J, Hettinga FJ. Pacing and decision making in sport and exercise: the roles of perception and action in the regulation of exercise intensity. Sports Med, 2014; 44(6): 763-775

Sterkowicz S, Lech G, Blecharz J. Effects of laterality on the technical/tactical behavior in view of the results of judo fights. Arch Budo, 2010; 1(6): 173-177

Sterkowicz S, Sacripanti A, Sterkowicz-Przybycien K. Techniques frequently used during London Olympic judo tournaments: a biomechanical approach. Available at: https://arxiv.org/ftp/arxiv/papers/1308/1308.0716.pdf; accessed on 28.07.2017

Sterkowicz-Przybycien K, Miarka B, Fukuda D. Sex and Weight Category Differences in Time-Motion Analysis of Elite Judo Athletes: Implications for Assessment and Training. J Strength Cond Res, 2017; 31(3): 817-825

Swart J, Lindsay TR, Lambert MI, Brown JC, Noakes TD. Perceptual cues in the regulation of exercise performance-physical sensations of exercise and awareness of effort interact as separate cues. Br J Sports Med, 2012; 46(1): 42-48

Tomazini F, Pasqua LA, Damasceno MV, Silva-Cavalcante MD, de Oliveira FR, Lima-Silva AE, Bertuzzi R. Head-to-head running race simulation alters pacing strategy, performance, and mood state. Physiol Behav, 2015; 1(149): 39-44

Tirp J, Baker J, Weigelt M, Schorer J. Combat stance in judo - Laterality differences between and within competition levels. Int J Perform Anal Sport, 2014; 14(1): 217-224

\section{Corresponding author:}

\section{Bianca Miarka}

Physical Education School, Federal University of Pelotas

Av. Eduardo Roberto Daher, n.567 - Centro, Itapecerica da Serra - SP, Brazil.

ZIP: 06850-040, Brazil

E-mail: miarkasport@hotmail.com 